\title{
Ethical Aspects of Crowdsourcing, or is it a Modern Form of Exploitation
}

\begin{abstract}
Aleksejs Busarovs ${ }^{1}$
Abstract:

Crowdsourcing is an online, distributed problem-solving and production model, first crowdsourcing mentioning in literature is dated in 2006. Crowdsourcing is new phenomenon in business, which appeared due to new possibilities of Web 2.0. Main Crowdsourcing advantage for entrepreneurs is opportunity to cut labour costs. Part of Crowdsourcing opponents criticizing it for human exploitation. Present paper has two goals, first of all to find out what does exploitation really mean from philosophical perspective and the second to determine Crowdsourcing activities participant's attitude to the fact of exploitation. The biggest part of previous research was dedicated to contributors' motivation, what moves them to take part in certain project. This work scrutinize participant's attitude to their previous experience in Crowdsourcing and motivation to repeat it again, that has substantial importance to Crowdsourcing sustainability in long term perspective. Taking into account, that method itself is realized by means on Internet, the research is conducted on-line, based on Crowdsourcing intermediate platform "Amazon Mechanical Turks", and has wide geographical coverage. Present research is interesting not only to academia circles, but also to socially responsible entrepreneurs, who is interested in applying this tool, maintaining high level of ethics and moral.
\end{abstract}

Key Words:

Crowdsourcing

JEL Classification: M140 Corporate Culture; Social Responsibility

\footnotetext{
${ }^{1}$ Riga International School of Economics and Business Administration, e-mail: alex@inomaniacs.eu
} 


\section{Introduction}

Crowdsourcing is rapidly developing concept, first time it was mentioned by Jeff Howe in his article "The rise of Crowdsourcing" (Howe, 2006), later in his book Crowdsourcing: Why the Power of the Crowd is Driving the Future of Business he developed definition of Crowdsourcing, which states, that Crowdsourcing is act of outsourcing tasks, traditionally performed by an employee or contractor, to an undefined, large group of people or community (a "crowd"), through an open call. (Howe, 2008). Researcher Daren Brabham from University of Utah regards Crowdsourcing as model for problem solving and production (Brabham, 2008). This paper research production's part of Crowdsourcing, where by means of Internet, wide worker's audience is attracted to perform simple tasks, which can't be automated. According Crowdsourcing classification, this type of tasks are routine tasks (Schenk and Guitard, 2009), example of this type of Crowdsourcing is image recognition and labelling. In spite of Crowdsourcing main advantage - low labour costs -, it has several shortcomings, such as: cheating (Chen, et al., 2010), complicated quality control system (Kittur, Chi, and Bongwon, 2008) and ethics violation by exploiting and underpaying workforce (Postigo, 2003; Cove, 2007). This research search answers for questions - is the Crowdsourcing labour exploitive practice from point of theory on exploitation, and how do workers feel exploited participating in Crowdsourcing activities?

\section{Related work}

At present moment there are three main groups of theories, which describes labour exploitation, they are: Marxist theory, Neo-classical theories and New Liberal theories. Traditionally under capitalism worker voluntarily make an agreement with employer. He can cancel this agreement at any time and make new one with another employer. Both parties have equal rights in this deal. There is no physical compulsion to work, or removal of work results. From said above can be drawn conclusion that exploitation doesn't exist under capitalism.

According to Marxist theory in capitalistic economy, capitalist, as owner of means of production, appropriates difference between new value, created by workers, and labour costs in form of workers wage (surplus value). The reason for this appropriation is private property rights on means of production. We need to take into consideration that surplus value is base for not only profit, but all type of taxes, excise, duties, rents, bank commissions. That is why, according to Marxist theory, workers are exploited, not only by capitalists, but moderately by state, merchandisers, intermediates, land lords, banks and their investors.

Karl Marx described rate of exploitation as ratio between surplus value and value of work force, in other words ratio between time that worker creates value for others 
and time of work for himself (creating equivalent own wage), as bigger is this value, then rate of exploitation is higher (Marx, 1867). In order to capitalistic exploitation can exist, the following elements should be met:

- Mass production means are in private property;

- Workers can't survive without selling own work force;

- Productivity of wage work are higher than no hired labour;

- State protecting private property rights.

Crowdsourcing partially corresponds with criteria required for exploitation existence, according to Marxist theory, especially in case of Mturk, since this Internet platform originates from USA, where state protecting private property rights, workers can't survive without selling their work force, mass production means are in private property, but because Internet as industry have low barriers to enter, any worker can become an employer, or capitalist according to Marxist theory. One question remains open - about productivity of capitalist's work and worker labour, in modern society both extremes are present low and high productivity of capitalist, which even called as self exploitation (Galbraith, 1973).

According to social liberals state must to interfere in economic process in order to fight against monopoly and sustaining competitive market environment. Society should have legal rights to extract part of person's income, if this income doesn't correspond with this person's contribution to common good, in form of taxes and redirect these taxes for social needs. Increase of level of living for lowest classes of society will enhance domestic market and growth of economy. Applying these approaches, according to social-liberals will soften tension in society and gradually transform capitalism of free market to social economy, based on private property and regulated market relationships (Faulks, 1999).

Non Marxist theories, or Neo-classsical theories, also has negative attitude towards exploitation, but consider as necessary element of free market economy, which diminished with its development. They state, that new value is created with equal participation of all factors of production, but not only by hired workers. Alfred Marshall wrote: "Capital in general and labour in general co-operate in the production of the national dividend, and draw from it their earnings in the measure of their respective (marginal) efficiencies. Their mutual dependence is of the closest; capital without labour is dead; the labourer without the aid of his own or someone else's capital would not long be alive. Where labour is energetic, capital reaps a high reward and grows apace; and, thanks to capital and knowledge, the ordinary labourer in the western world is in many respects better fed, clothed and even housed than were princes in earlier times. The co-operation of capital and labour is as essential as that of the spinner of yarn and the weaver of cloth: there is a little priority on the part of the spinner; but that gives him no pre-eminence. The prosperity of each is bound up with the strength and activity of the other; though each may gain temporarily, if 
not permanently, a somewhat larger share of the national dividend at the expense of the other." (Marshall, 1890). After conducting research of the modern literature on exploitation, following definitions of exploitation were found, they are arranged in three groups according their relevance to Crowdsourcing, 1 - Crowdsourcing completely corresponds with presented definition; 2 - Crowdsourcing partially corresponds with presented definition; 3 - Crowdsourcing doesn't correspond with presented definition of exploitation.

1 - Crowdsourcing completely corresponds with presented definition:

- "Exploitation necessarily involves benefits or a gain of some kind to someone ... Exploitation resembles a zero-sum game, viz. what the exploiter gains, the exploiter loses; or, minimally, for the exploiter to gain, the exploiter must lose." (Tormey, 1974). In this definition Crowdsourcing is example of exploitation. Worker is spending his/her time, without minimum compensation, defined by law. In this case worker spending only his time, since routine Crowdsourcing doesn't require special skills, except basic computer literacy. Employer from other side receives results of workers' labour, which would cost considerably more in case of traditional employment.

- "Exploitation of persons consists in ... wrongful behaviour [that violates] the moral norm of protecting the vulnerable." (Goodin, 1988a). This completely describes Crowdsourcing; employer's behaviour violates moral norms, because people are employed without social safeguards and without paying social and income tax. Even if law can't protect rights of diminished, the abuse of moral norms is obvious.

- "Common to all exploitation of one person (B) by another (A)...is that a makes a profit or gain by turning some characteristic of B to his own advantage...exploitation ... can occur in morally unsavoury forms without harming the exploitee's interests and ... despite the exploiter's fully voluntary consent to the exploitative behaviour..." (Feinberg, 1988). Perfect example of exploitation in Crowdsourcing, where B is spending his/her time for profit of A, with fully voluntary consent and without any harm for himself.

- "A group is exploited if it has some conditionally feasible alternative under which its members would be better off." (Roemer, 1986) Good description of Crowdsourcing activities, workers have alternative to search traditional work, where law oblige employer to sustain minimum wage and social safeguards, what is not present in Internet domain, thus alternative is substantially better for workers.

- "Exploitation is seen as the failure to pay labours its marginal product..." (Brewer, 1987). Probably this is correspondence, because worker in Crowdsourcing receive insignificantly income, but the work itself is primitive and as well insignificant, more thorough research is needed to 
determine real value of marginal product, then it will be clear, is Crowdsourcing exploitive practice, according to this point of view.

- "An exploitative exchange is... an exchange in which the exploited party gets less than the exploiting party, who does better at the exploited party's expense... The exchange must result from social relations of unequal power ... exploitation can be entered into voluntarily; and can even, in some sense, be advantageous to the exploited party." (Levine, 1988). This is complete correspondence with Crowdsourcing; there is voluntary participation in activities, in which workers receive less then than employer.

- "Workers are exploited if they work longer hours than the number of labour hours employed in the goods they consume." (Elster, 1986). Complete correspondence with Crowdsourcing, since wage in Crowdsourcing run into cents, thus in order to buy goods offered in Amazon, workers need substantially more time to earn this money, then time needed for product production. Mturk doesn't offer direct monetization for non-US and non-Indian residents, all earned money can be used only for goods purchasing through Amazon website (Amazon, 2011).

2 - Crowdsourcing partially corresponds with presented definition.

- "To exploit a person involves the harmful, merely instrumental utilization of him or his capacities, for one's own advantage or for the sake of one's own ends." (Buchanan, 1985). This statement partially corresponds with Crowdsourcing, because it has no harm, since every person is responsible for environment he has access to the Internet, employer doesn't imply no restrains or conditions.

- "It is the fact that the [capitalist's] income is derived through forced, unpaid, surplus [wage] labour, the product of which the workers do not control, which makes [wage labour] exploitive." (Holmstrom, 1997). Partial correspondence, workers indeed have no control over product, and unpaid surplus goes to capitalist, what make Crowdsourcing so appealing, but there is no forced behaviour, since employer has no tools to coercion. Internet offers wide variety of choice, even in such domain, as routine Crowdsourcing, without any additional cost to change employer.

- "There are four conditions, all of which must be present if dependencies are to be exploitable. First, the relationship must be asymmetrical ... Second, ... the subordinate party must need the resource that the superordinate supplies ... Third, ... the subordinate party must depend upon some particular superordinate for the supply of needed resources ... Fourth, the superordinate ... enjoys discretionary control over the resources that the subordinate needs from him..." (Goodin, 1988b). Due 
to the fact, that author of this definition determined hard conditions for exploitation; I could state that Crowdsourcing partially corresponds with this statement. Since relationships is definitely asymmetrical, because there is almost perfect competition in labour market in the Internet, and lack of workers protection by law, as well employer enjoys control, since last insure him super profit, which would be impossible to receive in case of traditional employment. Simultaneously, despite fact that employer is needed the resource, or workers, he has opportunity to hire them not in the Internet, where he came in search of cutting costs, thus it would be inappropriate to talk about need. Regard concerning particular employer is unsound, this notion is supported by Crowdsourcing definition, which describes undefined group of people, in other words - crowd.

- "Persons are exploited if (1) others secure a benefit by (2) using them as a tool or resource so as (3) to cause them serious harm." (Munzer, 1990). Partial correspondence, definitely employer use workers as cheap resource for increasing profit, but there is no serious harm, the same as in case of definition on exploitation by Buchanan.

- "[Capitalist] social relations ... are exploitative, not only in the specific sense of extracting surplus labour, but in the more general sense of using someone as a means, utilizing her to detriment as a way of promoting one's own good..." (Kymlicka, 1989). Partial correspondence, since there is no harm in Crowdsourcing, but obtaining surplus labour remains.

- "Exploitation forms part of an exchange of goods and services when (1) the goods and services exchanged are quite obviously not of equivalent value, and (2) one party to the exchange uses a substantial degree of coercion." (Moore, 1973). Partial correspondence, since in Crowdsourcing there is no even minimal coercion, not talking about substantial degree of it, but goods are exchange not equally, if compare labour time and scanty earnings.

3 - Crowdsourcing doesn't correspond with presented definition of exploitation.

- "Exploitation [in exchange] demands ... that there is no reasonably eligible alternative [for the exploiter] and that the consideration or advantage received is incommensurate with the price paid. One is not exploited if one is offered what one desperately needs at a fair and reasonable price." (Benn, 1988). In spite of fact, that in this case present such elements, as unfair and unreasonable price, still we need to look down to the essence of the definition, which mentioned lack of alternative and desperate need. Participation in Crowdsourcing activities itself is alternative to traditional employment, or even to the entertainment, in addition, desperate need is correlated with basic human needs, but Crowdsourcing require access to the Internet, what can be 
interpreted, that basic human needs, according to Maslow, were satisfied, people won't starve in order to spend one hour online.

- "A society is exploitative when its social structure is organized so that unpaid labour is systematically forced out of one class and put at the disposal of another ... On the force-inclusive definition of exploitation; any exploitative society is a form of slavery." (Reiman, 1987). This statement has nothing in common with Crowdsourcing, since it lacks forceful compulsion to participate in it.

- "Exploitation is a psychological, rather than a social or an economic, concept. For an offer to be exploitative, it must serve to create or to take advantage of some recognized psychological vulnerability which, in turn, disturbs the offeree's ability to reason effectively." (Hill, 1994). This definition doesn't describe Crowdsourcing, because tasks aren't meant for particular group of people, who have certain psychological weakness, the essence of Crowdsourcing, that group, which executing tasks is undetermined.

Summarized, mentioned above definitions, purely from theoretical point of view, Crowdsourcing can be determined as exploitive practice, since seven out of sixteen definitions of exploitation describe Crowdsourcing as exploitation, six do it partially, and only according to three definitions Crowdsourcing isn't an example of exploitation. All definitions of exploitation are presented in Figure 1. Field research should reveal, what workers think about them being exploited.

Figure 1: Summary of exploitation's definitions

\begin{tabular}{|c|c|c|c|c|c|c|c|c|c|c|c|c|c|c|c|c|}
\hline & 总 & 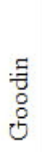 & 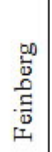 & 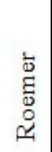 & 离 & 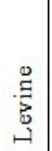 & $\frac{\frac{\vec{d}}{\frac{D}{D}}}{\frac{1}{|c|}}$ & 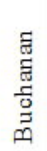 & 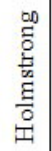 & $\begin{array}{l}: \tilde{7} \\
\circ \\
\circ \\
0\end{array}$ & $\begin{array}{l}\stackrel{\breve{s}}{\mathrm{~N}} \\
\stackrel{\Xi}{\Xi}\end{array}$ & 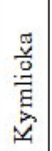 & $\begin{array}{l}0 \\
\sum_{0}^{\circ} \\
0\end{array}$ & 志 & 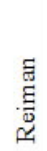 & $\bar{\Xi}$ \\
\hline Surplus is acquired by employer & $\sqrt{ }$ & & $\sqrt{ }$ & & $\sqrt{ }$ & $\sqrt{ }$ & $\sqrt{ }$ & $\sqrt{ }$ & $\sqrt{ }$ & $\sqrt{ }$ & $\sqrt{ }$ & $\sqrt{ }$ & $\sqrt{ }$ & $\sqrt{ }$ & $\sqrt{ }$ & \\
\hline Inequality, moral norms violation & & $\sqrt{ }$ & $\sqrt{ }$ & & & $\sqrt{ }$ & & & & $\sqrt{ }$ & & $\sqrt{ }$ & & & & $\sqrt{ }$ \\
\hline Harmful & & & & & & & & $\sqrt{ }$ & & & $\sqrt{ }$ & & & & & \\
\hline None harmful & & & $\sqrt{ }$ & & & & & & & & & & & & & \\
\hline Forced, controlled participation & & & & & & & & & $\sqrt{ }$ & $\sqrt{ }$ & & $\sqrt{ }$ & $\sqrt{ }$ & & $\sqrt{ }$ & \\
\hline Voluntary participation & & & $\sqrt{ }$ & & & $\sqrt{ }$ & & & & & & & & & & \\
\hline Lack of altematives & & & & $\sqrt{ }$ & & & & & & & & & & $\sqrt{ }$ & & \\
\hline Need for supply & & & & & & & & & & $\sqrt{ }$ & & & & $\sqrt{ }$ & & \\
\hline
\end{tabular}

\section{Methodology}

Amazon Mechanical Turk, or Mturk is Internet website for execution simple tasks, by big number of people. This website was created in 2005, in 2007 there were 100.000 workers (Pontin, 2007), two years latter it grew up to 400.000 members 
(Kolakowski, 2009), and unfortunately Mturk doesn't reveal information on current number of workers. Biggest part of it contributors are from USA and India (Ross et. al., 2010), this mainly explained by limited opportunities to withdraw earned money, only residence of this two countries can transfer their earning to their bank account, or receive them in form of cheque, all the world could only transfer their earnings to gift certificate at Amazon.com, and use it for purchasing at Amazon.com. We can make assumption that by making process of earned money withdrawal easier, for example through major Internet money transfer website, like PayPal, number of participants from countries with low income will grow dramatically. The structure of process at Mturk is as follows, requester brakes Project in to tasks, then publish them in the Internet, workers accept assignment, execute and submit for evaluation, in case of approval workers receives compensation (Figure 2). Mturk collects commission 10\%, but not less then 0.0005 USD, there is possibility to hire only experienced workers, who earlier showed high quality performance, in this case commission will be $20 \%$.

Figure 2: Process algorithm at Mturk.com

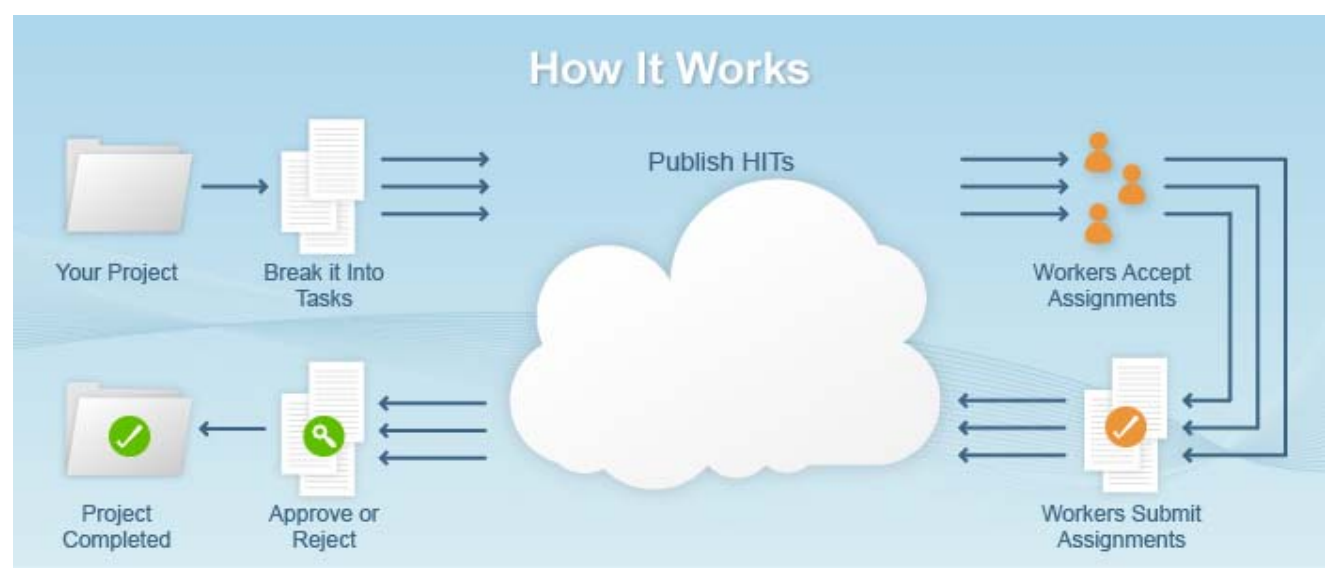

Source: www.mturk.com

Conducting research among Mturk users, there was administrative barrier, according to Amazon polices requesters must provide valid postal USA address in order to register with Mturk. This barrier was overcome thanks to cooperation with American partners, who provided access to Mturk website, therefore I want to express acknowledgement to my American partner Deniss Strulevich. Total budget of this research was limited to $200 \mathrm{USD}$, and price for one assignment, or HIT (Human Intelligence Tasks), initially was determined as 0.05 USD in order to maximize efficiency between HIT's price and commission to Amazon. Respond rate was slower then expected, and error in HIT's html code was discovered, what made first responses unusable, in terms of their attitude toward exploitation. Taking into account these two facts, new survey was launched, after correcting html code, and 
higher price was set -0.20 USD -, in order to speed up response rate. The survey consisted of three parts, first, one asked general information about age, gender, experience in Crowdsourcing and their feelings towards fact of exploitation. The second part provided quote from J. Feinberg: "Common to all exploitation of one person (B) by another (A)...is that A makes a profit or gain by turning some characteristic of $\mathrm{B}$ to his own advantage...exploitation ... can occur in morally unsavoury forms without harming the exploiter's interests and ... despite the exploiter's fully voluntary consent to the exploitative behaviour...". The third part again asked questions about exploitation and plans to participate in Crowdsourcing activities in future. In order to reduce fraud attempts checking question was imbedded, as well time was monitored time spend on this HIT, which helped to eliminate answers provided by automated virtual robots. Each contributor could complete this HIT only once, and all workers with minimum experience could participate in this survey - no restriction was made.

Even that budget allowed bigger sample size, due limitation in time and low response rate, the sample size is 320: 29 answers were not taken into account because they was illegitimate; 19 didn't completed survey properly, providing less or more answers, or didn't provide correct information about their age, or experience (1 person claimed, that his experience with Mturk is 96 months, what would made him register on this website in 2003 which is impossible because Mturk was launched in 2005); 10 persons didn't manage to answer correctly for checking question. Question about exploitation perception was: "Do you think you are being exploited completing HITs?". Scale of answers of five options from "not exploited" (0) to "very exploited" (4) was offered. Average results for the first part is 1.03 , which is interpreted as "slightly exploited", after reading provocative definition on exploitation the results raised insignificantly till 1.13, which still corresponds with "slightly exploited". More detailed answers distribution is presented in Figure 3, where answers in group A is initial response, and answers in group B is response after reading provocative definition. Willingness to complete HITs in the future was overall positive, the question was: "Are you going to complete HITs in the future?" answers was scale of five, from "definitely no" (-2) to "definitely yes" (2), result was 1.73 , after second round it reduced till 1.68. More detailed answers distribution is presented in Figure 4, where answers in group $\mathrm{A}$ is initial response, and answers in group B is response after reading provocative definition. Conclusion is that Mturk workers don't feel being exploited and ready to this work in future, but are slightly influenced by explanatory information. 
Figure 3: Answers to question: "Do you think you are being exploited completing HITs?”

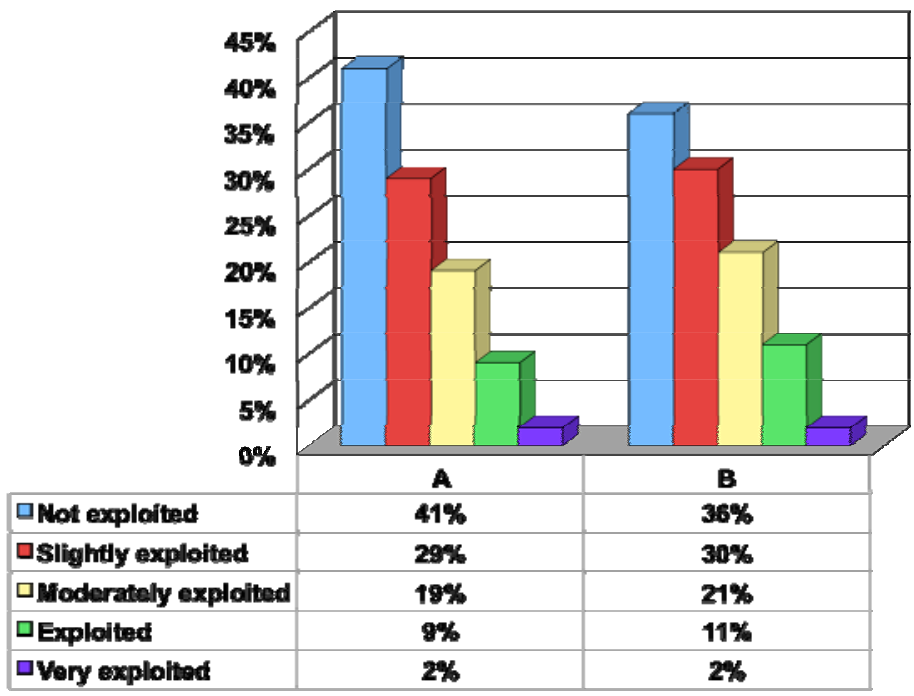

Figure 4: Answers to question: “Are you going to complete HITs in the future?”

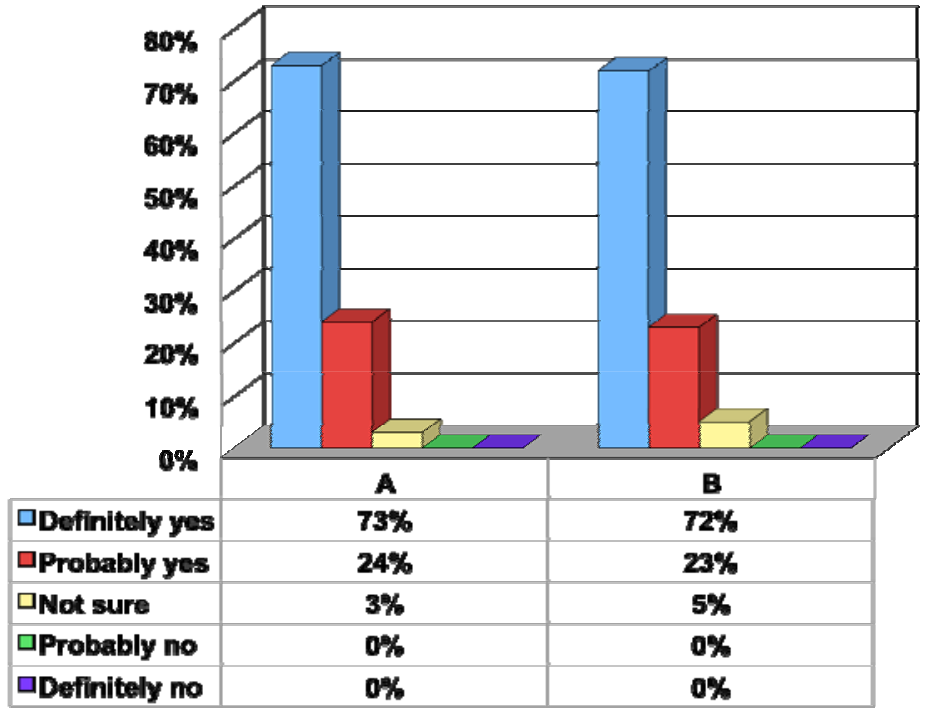

\section{Future work}

Future Crowdsourcing research on its ethical aspects should cover not only production part of Crowdsourcing but problem solving as well, or complex and 
creative types of Crowdsourcing. Especially creative type, because usually it has form of idea contest, where no guaranties that idea will be chosen as wining one, and work compensated, in spite of time and afford invested in solving particular problem.

\section{Conclusion}

Crowdsourcing develops rapidly with new features of Web 2.0 legislators, whose objective is protection of workers, as citizens, are lagging behind new realities. But in case of Internet, and Crowdsourcing particularly, this lag is positive aspect, since non-interference from government, gives this method freedom to develop naturally towards its absolute and harmonic form, to which going all the inventions (Altshuler, 1984). Results show that workers don't feel themselves being exploited and ready to participate in Crowdsourcing activities in future, this situation Wertheimer describes as mutual agreement, and claim that in this circumstances government interference is not necessary (Wertheimer, 2008). This notion, together with this survey results, gives rights to state, that even with its shortcoming and ambiguity from theoretical point of view, Crowdsourcing doesn't violate ethical norms of worker and employer. Especially in global environment of Internet, with equal opportunity for third world countries, where small compensation of routine Crowdsourcing is adequate income, due to low level of prices.

\section{References}

Altshuller, G.S. (1984), Creativity as an exact science, translated by Williams, A., Gordon \& Breach Science Publisher, NY, London.

Amazon (2011), FAQ, available at: www.mturk.com/mturk/help?helpPage=worker\# how_paid.

Benn, S. (1988), A Theory of Freedom, Cambridge University Press, Cambridge.

Brabham, D.C. (2008), "Crowdsourcing as a Model for Problem Solving: An Introduction and Cases, Convergence", The International Journal of Research into New Media Technologies, 14(1), pp. 75-90.

Brewer, J. (1987), "Exploitation in the New Marxism of Collective Action", Sociological Review, 35, pp. 84-96.

Buchanan, A. (1985), Ethics, Efficiency, and the Market, Rowman and Allanheld, Totowa: N.J.

Chen, K.T., Chang C.J., Wu, C.C., Chang, Y.C., Lei, C.L. and Sinica, C. (2010), "Quadrant of Euphoria: A Crowdsourcing Platform for QoE Assessment", Proceedings of IEEE Network, 24(2), pp. 28-35.

Cove, S. (2007), What does Crowdsourcing Really Mean? Wired news: Assignment Zero, (July 12), available at www.wired.com/techbiz/media/news/2007/07/crowdsourcing [accessed Sept. 12, 2011].

Elster, J. (1983), Exploitation, Freedom, and Justice in Pennock, J.R. and Chapman, J. (Eds.) Nomos XXVI: Marxism, New York University Press, New York, pp. 227-52. 
Faulks, K. (1999), Political Sociology: A Critical Introduction, MPG Books, Bodmin.

Feinberg, J. (1988), Harmless Wrongdoing, Oxford University Press, Oxford.

Galbraith, J.K. (1973), Economics and the Public Purpose, Houghton Milfin Company, Boston.

Goodin, R. (1988a), Reasons for Welfare, Princeton University Press, Princeton.

Goodin, R. (1988b), "Reasons for Welfare: Economic, Sociological, and Political — But Ultimately Moral" in Donald Moon, J. (Ed.), Responsibility, Rights, and Welfare, Westview Press, Boulder Co., pp. 19-54.

Hill, J.L. (1994), Exploitation, Cornell Law Review, 79, pp. 631-99.

Holsmstrom, N. (1997), Exploitation, Canadian Journal of Philosophy, 7, pp. 353-69.

Howe, J. (2006), The Rise of Crowdsourcing, available at www.wired.com/wired/archive/ 14.06/crowds.html (wired, June).

Howe, J. (2008), Crowdsourcing: Why the Power of the Crowd Is Driving the Future of Business, New York, Three Rivers Press.

Kittur, A., Chi, E. and Bongwon, S. (2008), "Crowdsourcing User Studies With Mechanical Turk", Proceedings of CHI 2008, April 5-10, Florence, Italy.

Kolakowski, N. (2009), "Amazon.com Advocates Crowdsourcing, Mechanical Turk in NYC", eWeek.com, November.

Kymlicka, W. (1989), Liberalism, Community and Culture, Clarendon Press, Oxford.

Levine, A. (1988), Arguing for Socialism, Verso, London.

Marshall, A. (1890), Principles of Economics, Cosimo Classics, New York.

Marx, K. (1867), Capital, Penguin Books, London.

Moore, B. (1973), Reflections on the Causes of Human Misery, Beacon Press, Boston.

Munzer, S. (1990), A Theory of Property, Cambridge University Press, Cambridge.

Pontin, J. (2007), “Artificial Intelligence with Help from the Humans", New York Times, March.

Postigo, H. (2003), "From Pong to Planet Quake: Post-Industrial Transitions from Leisure to Work", Information, Communication and Society, 6(4), pp. 593-607.

Reiman, J. (1987), "Exploitation, Force, and the Moral Assessment of Capitalism: Thoughts on Roemer and Cohen", Philosophy and Public Affairs, 16, pp. 3-41.

Roemer, J. (1985), "Should Marxists Be Interested in Exploitation?", Philosophy and Public Affairs, 14, pp. 30-65.

Ross, J., Irani, L., Silberman, M.S., Zaldivar, A. and Tomlison, B. (2010), "Who are the Crowdsourcers? Shifting Demographics in Mechanical Turk", Proceedings of CHI2010: Imagine all the People, April 10-15, Atlanta, GA, USA, pp. 2863-2872.

Schenk, E. and Guitard, C. (2009), "Crowdsourcing: What can be Outsourced to the Crowd, and Why?" halshs-00439256, ver. 1, - December 8.

Tormey, J.F. (1974), "Exploitation, Oppression and Self-Sacrifice", Philosophical Forum, 5, pp. 206-21.

Wertheimer, A. (2008), "Exploitation", The Stanford Encyclopaedia of Philosophy (Fall Edition), Zalta, E.N. (Ed.), available at http://plato.stanford.edu/archives/fall2008/ entries/ exploitation/. 